This item was submitted to Loughborough's Research Repository by the author.

Items in Figshare are protected by copyright, with all rights reserved, unless otherwise indicated.

\title{
Quantification of slope displacement rates using acoustic emission monitoring
}

PLEASE CITE THE PUBLISHED VERSION

PUBLISHER

(C) NRC Research Press

VERSION

AM (Accepted Manuscript)

LICENCE

CC BY-NC-ND 4.0

\section{REPOSITORY RECORD}

Dixon, Neil, and M.P. Spriggs. 2019. "Quantification of Slope Displacement Rates Using Acoustic Emission Monitoring". figshare. https://hdl.handle.net/2134/4374. 
This item was submitted to Loughborough's Institutional Repository (https://dspace.lboro.ac.uk/) by the author and is made available under the following Creative Commons Licence conditions.

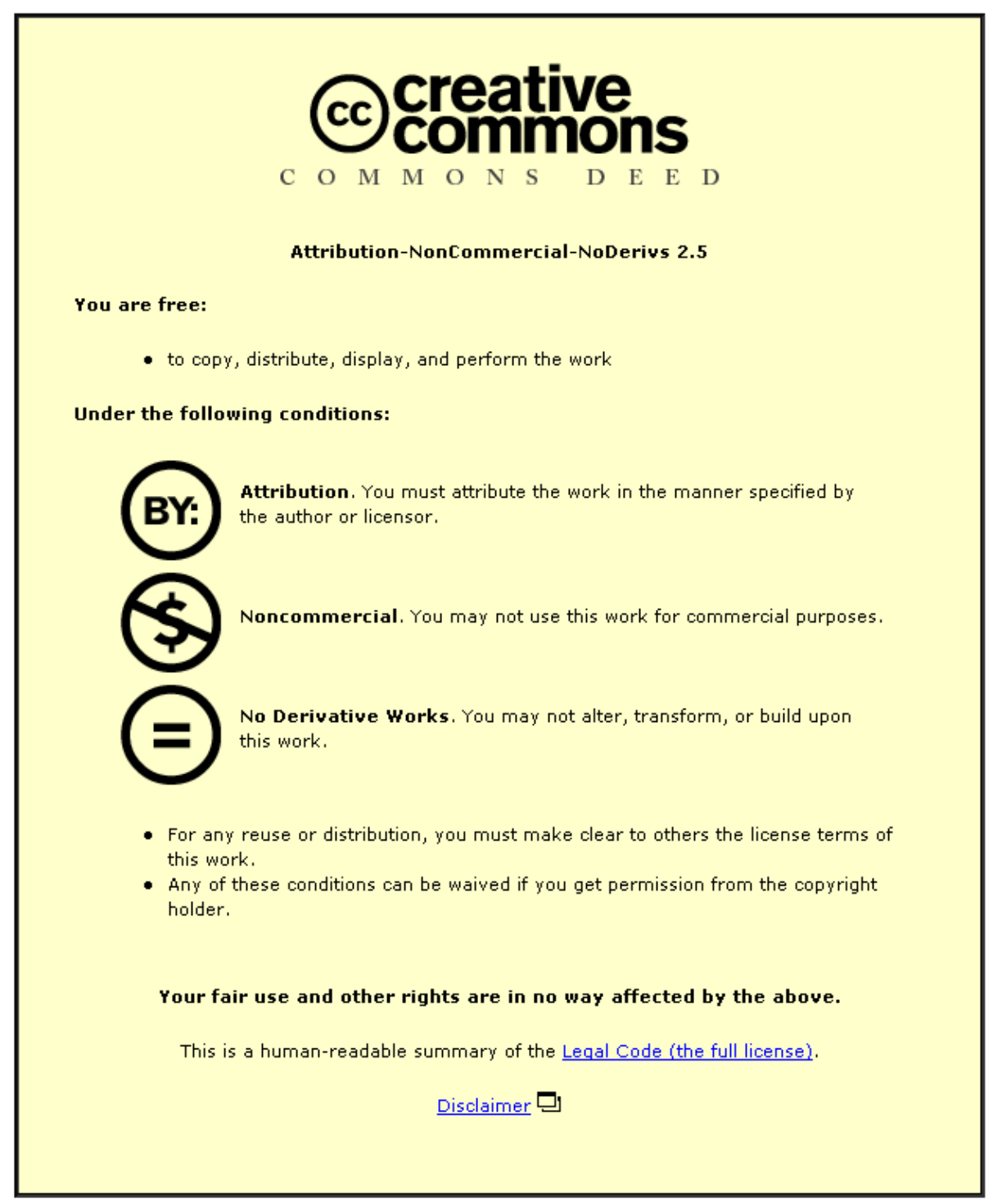

For the full text of this licence, please go to: http://creativecommons.org/licenses/by-nc-nd/2.5/ 
Dixon, N. and Spriggs, M. (2007). Quantification of slope displacement rates using acoustic emission monitoring. Canadian Geotechnical Journal, 44, 6, 966-976.

\title{
Quantification of Slope Displacement Rates Using Acoustic Emission Monitoring
}

\author{
N. Dixon* \& M. Spriggs+
}

* Senior Lecturer in Geotechnical Engineering, Department of Civil and Building Engineering, Loughborough University, LE11 3TU, United Kingdom, Email: n.dixon@lboro.ac.uk, Tel: 0044 (0)1509 228542, Fax: 0044 (0)1509 223981 (Corresponding author)

$+\quad$ Research Assistant, Department of Civil and Building Engineering, Loughborough University, Leicestershire, LE11 3TU, UK

4,600 Words, 4 Tables, 7 Figures 


\section{Abstract}

In soil slopes, developing shear surfaces generate acoustic emission (AE). The Authors have previously proposed the use of active waveguides for monitoring the stability of such slopes. Active waveguides comprise of a steel tube installed in a preformed borehole through a slope with coarse grained soil backfill placed in the annulus around the tube. Deformation of the host soil generates AE in the active waveguide. Field trials of this system reported previously have shown that AE rates are linked to slope deformation rates. This paper extends the study by detailing a method for quantifying slope movement rates using an active waveguide. A series of laboratory experiments are presented and used to define the relationship between AE event count rate and displacement rate. The method was shown to differentiate rates within an order of magnitude, which is consistent with standard landslide movement classification (i.e. 1 to $0.001 \mathrm{~mm}$ per minute), using a relationship derived between the gradient of the event count rate with time and deformation rate. In addition, it was possible to detect a change in displacement rate within two minutes of it occurring even at very slow rates (i.e. $0.0018 \mathrm{~mm} / \mathrm{min}$ ). Knowledge of changes in displacement rate is important in situations where slope movements are suddenly triggered or displacements accelerate in response to a destabilising event. Field trials of a realtime AE monitoring system are currently in progress to compare performance against traditional instrumentation.

\section{Key words}

Instrumentation, acoustic emission, slope instability 


\section{Introduction}

For many countries world-wide landslides can be the most severe of all natural disasters, with large humanitarian and economic consequences. The ongoing need to develop new techniques that can be used to lessen damage and loss of life caused by slope instability is self-evident. Of particular concern are slopes formed in strainsoftening materials (e.g. plastic clays and shales) and those which incorporate discontinuities with strain softening behaviour (e.g. joint/bedding surfaces and fault zones), which can experience progressive failure and hence undergo deformation prior to collapse. In these types of materials, shear deformations of the order of a few tens of millimetres may be sufficient to reduce shear strength to post-peak values leading to rapid and potentially catastrophic slope failure. The earlier that decreasing stability can be detected, the earlier a warning can be given to those likely to be affected by any event, thus allowing evacuation or remedial measures to arrest the movements.

Materials undergoing deformation generate acoustic emission (also known as subaudible noise). Studies of AE have sought to use capture and measurement of the signal to determine the extent of material deformation. In soil, acoustic emission is generated from inter-particle friction and in rock by fracture propagation and displacement along discontinuities (also referred to as microseismic and rock noise). The presence of AE is an indication of microscopic defect growth or localised inter-particle displacements within the soil or rock body. Within a soil slope the shear stresses induced by destabilising forces cause re-arrangement of particles along developing shear surfaces and this generates AE. 
Detecting AE generated within a slope is challenging. Fine grained soils (i.e. silt and clay dominated) generate low levels of AE when sheared (Koerner et al. 1981). Even if the host soil is considered to be relatively noisy (i.e. a coarse grained soil), attenuation of generated $\mathrm{AE}$ is very high due to energy loss as $\mathrm{AE}$ is transferred from one particle to another. Shiotani \& Ohtsu (1999) demonstrated that at $30 \mathrm{kHz}$, a signal is attenuated by over $100 \mathrm{~dB}$ when it propagates $100 \mathrm{~mm}$ in a sand. For these reasons, Dixon et al. (2003) have proposed the use of active waveguides for monitoring soil slopes. This system comprises installation of a steel tube in a pre-formed borehole with coarse grained soil backfill (e.g. sand or gravel) placed in the annulus around the tube. The tube and soil surround composite is termed the active waveguide. Deformation of the host soil body generates deformation, and hence AE, in the active waveguide, which is transmitted to a sensor at the ground surface. Through a series of field trials, Dixon et al. (2003) demonstrated that the active waveguide produced detectable $\mathrm{AE}$ in response to periods of slope instability. AE rates were shown to be linked to slope deformation rates and AE monitoring indicated the onset of instability before traditional deformation monitoring techniques. This study showed that $\mathrm{AE}$ monitoring could be used to provide an early warning of slope instability. The current paper extends the work of Dixon et al. (2003) by detailing a method for quantifying slope movement rates, and changes in these displacement rates with time, using detected AE from an active waveguide. Previous research has used relatively expensive pre-fabricated waveguide elements such as the glass fibre reinforced resin filled double tube waveguide described by Nakajima et al. (1991), to relate AE and slope instability. 


\section{Slope displacement rates}

Monitoring of potentially unstable slopes has three primary objectives: to detect displacements as early as possible, to measure the rate of displacements and to detect and quantify changes in the rate of displacement. To provide timely (i.e. early) information on slope instability, including the timing and likely significance of the potential failure event, requires all three objectives to be met. It is common practice to classify slope deformations using descriptive terms related to magnitudes of displacement rate. An example produced by the Transport Research Board (1978) is shown in Table 1 and has been adopted for this study. The descriptors of displacement rate (i.e. rapid, moderate, slow and very slow) are related to, and hence separated by, orders of rate magnitude. Magnitude and rate of displacements are typically monitored by instruments such as inclinometers, extensometers and using surface surveying techniques. Many of the techniques commonly in use require measurements made at time intervals to indicate slope movements and rates of change, and the resolution of displacements that can be detected is often in the order of a few millimetres. In some cases this will not provide sufficient time to allow a response to the monitoring output. However, in-place inclinometer strings and TDR systems are capable of providing real-time measurements of displacements. A major consideration when using these in-place instruments is that they are damaged by large displacements, becoming inoperable. This can be a significant problem in slopes with regular reactivated movements. The aim of ongoing research by the authors is to develop a real-time slope monitoring system using AE that is sensitive to small prefailure deformations (i.e. as detailed by Dixon et al. 2003), can detect slow displacement rates, and can be used to rapidly identify changes in displacement rate. This paper details research using active waveguides to differentiate between 
magnitudes of deformation rate (i.e. between rapid, moderate, slow and very slow rates) and assess sensitivity to rate changes.

To date, the application of AE to landslide monitoring has progressed only as far as a qualitative guide. Koerner et al. (1981) produced the most comprehensive qualitative framework using terms to describe the level of $\mathrm{AE}$ generation by a slope linked to a description of slope deformation rate and state. Koerner et al. (1981) proposed slopes that:

- Generate little or no $\mathrm{AE}$ - are probably not deforming and are therefore stable.

- Generate moderate levels of $\mathrm{AE}$ - are deforming slightly but marginally stable, continued monitoring is necessary.

- Generate high levels of AE - are experiencing substantial deformations, and are considered unstable with immediate remedial measures required.

- Generate very high levels of AE - are undergoing large deformations and are probably in a state of failure.

At the time of developing this guide there was a lack of information about generation and propagation of $\mathrm{AE}$, including the role of the waveguide, and hence it was not possible to quantify the AE levels or relate them to displacement rates. In addition, the highly variable magnitude of AE generated by deforming soils (i.e. between fine and coarse grained soils) means that it is not possible to set general AE levels to define the terms 'little' 'moderate', 'high' and 'very high'. It is evident that in order to successfully monitor and provide a warning of the onset and significance of failure, a quantitative output, in terms of rate of displacement with time, is essential. Using active waveguides, it has for the first time become possible to quantify displacement rates using measured $\mathrm{AE}$. 


\section{AE monitoring system}

A schematic representation of a typical slope $\mathrm{AE}$ monitoring system is shown in Figure 1. An active waveguide is installed in a pre-bored borehole through the slope, penetrating any potential shear zones. The deforming slope strains the waveguide backfill, generating AE that propagates along a steel waveguide to a piezoelectric sensor secured to the top of the waveguide. The signal from the sensor is passed through a pre-amplifier to strengthen the signal for transmission along a cable to the data capture and processing hardware. Here it is filtered to improve the signal to noise ratio and further amplified, and then converted to a digital signal for storage and analysis. Each element of the system is described in more detail below.

In this investigation, steel waveguides with a 55mm diameter and 3mm wall thickness were used for all experiments, as these have been shown to be effective in both laboratory and field applications (Dixon et al. 2003 and Kousteni, 2002). Steel has attenuation characteristics of $<0.1 \mathrm{~dB} / \mathrm{m}$ compared to that of soil, which can have attenuation rates that are $>4000 \mathrm{~dB} / \mathrm{m}$. Backfill for the active waveguide comprised sub-angular crushed river gravel with a nominal size of $5 \mathrm{~mm}$. Kousteni (2002) showed that whilst sand produced a larger number of $\mathrm{AE}$ events for a given deformation, gravel produced $\mathrm{AE}$ events of greater amplitude due to its increased particle size and hence larger forces required to re-arrange interlocked particles. Events of larger amplitude propagate further along a waveguide and are more easily detected by the sensor.

The sensor used for all experiments had a resonant frequency of $50 \mathrm{kHz}$ (Physical Acoustics Corporation R61-AST). The sensor was connected to the waveguide using 
a magnetic device with a layer of silicon gel to aid acoustic transfer (ASTM 2002). The pre-amplifier (Physical Acoustics Corporation 1220A) provided an amplification gain of either 40 or $60 \mathrm{~dB}$. Final amplification of the signal by between 0 and $41 \mathrm{~dB}$ gain was carried out before processing (Physical Acoustics Corporation 1221A). This incorporated a high pass filter of $10 \mathrm{kHz}$ and a low pass filter of $100 \mathrm{kHz}$. Filtering out frequencies less that $10 \mathrm{kHz}$ removes much of the potential background noise found on site or in the laboratory environment. Although attenuation of AE in soil is extreme at the high frequencies used for monitoring in this study, the short $\mathrm{AE}$ path length between the deforming backfill and steel tube results in propagation of detectable levels of $\mathrm{AE}$ at the sensor. The signal was converted from an analogue voltage input to a digital value at a maximum sampling rate of $1 \mathrm{MHz}$ (Adept Scientific $\mathrm{CIO}$ DAS16/M1). DASYLab software (Data log) was used to capture and carry out realtime and post signal processing. The software allowed further filtering of unwanted frequencies and setting of threshold amplitude levels to remove signal background noise. Quantification of AE used event count rates. An event consists of many threshold crossings of the signal and is characterised as beginning when the threshold is first crossed following a pre-determined period of time without a threshold crossing, and ending when the waveform falls and remains below the threshold for a pre-determined length of time. At high AE generation rates it is possible for events to overlap and be counted as one event, thus underestimating the event rates. However this underestimate does not change interpretation of the AE as discussed below.

\section{Active waveguide AE response}

Three types of laboratory experiments were conducted to investigate the relationship between deformation rates of an active waveguide system and generated AE. Firstly, 
model active waveguide compression tests were conducted. These used a simple waveguide configuration and compression system to enable repeatable tests to be carried out at a range of displacement rates. These tests were used to obtain the quantitative relationship between active waveguide deformation rate and $\mathrm{AE}$ event rate. Following these, three large scale tests were performed that included interaction between the waveguide backfill and host soil during shear deformation to validate the deformation/AE relationship under more realistic waveguide/host soil interaction conditions. Finally, blind compression tests were conducted to assess sensitivity of the approach to detect changes in displacement rate.

\section{Active waveguide compression tests}

The experimental procedure employed was proposed by Kousteni (2002). It entails installing the waveguide and backfill inside a flexible cylinder (i.e. to represent the borehole and support provided by the host soil), orientating the assembly horizontally and deforming the diameter using a standard compression machine. Figures 2a and $b$ show a diagram and photograph respectively of the test set up. The metal pipe waveguide was $3 \mathrm{~m}$ in length. The gravel backfill was placed around the waveguide inside a $2 \mathrm{~mm}$ thick high density polyethylene geomembrane sleeve and compacted to a density of $1500 \mathrm{~kg} / \mathrm{m}^{3}$. The geomembrane was used as it had sufficient rigidity to hold the gravel in place without overly restricting deformation. Wooden caps were fitted at each end of the geomembrane sleeve to prevent loss of gravel. A load ring was located between the loading frame and waveguide assembly, and contact shoes were used to distribute load to the geomembrane (i.e. to minimise unrepresentative point loading). The sensor was placed 1.8 metres from the loading position. Deformation rates were selected to mirror the Transport Research Board (1978) classifications and they are given in Table 1. Maximum deformations of the 
waveguide diameter were in the range 8 to $12 \mathrm{~mm}$. To assess laboratory levels of background noise, and hence define the amplitude threshold above which data would be recorded, AE monitoring was carried out during operation of the compression apparatus but without deforming the waveguide system. A threshold of 0.3 volts was selected to remove background noise (including any noise generated by the compression machine) and used in all tests reported in this paper. A total of 26 tests were conducted using four constant displacement rates.

Figure 3 is a plot of log event rate vs. log time for all of the compression tests. The results for tests carried out using each displacement rate form groups, demonstrating good repeatability. In addition, the clear banding of data provides a mechanism for differentiating magnitude of displacement rate using the $\mathrm{AE}$ event rates. The one deficiency of the data is that there was a 'settling down' period in each test, in which it was not possible to reliably distinguish the rate of displacement within the first $1 \mathrm{~mm}$ of deformation. This is why the data in Figure 3 does not start at time zero. The slower the displacement rate the longer the time until reliable data was obtained (i.e. time taken to achieve approximately $1 \mathrm{~mm}$ of displacement). It is considered that this behaviour is a function of the gravel/geomembrane sleeve interaction and the difficulty in achieving high backfill densities, as AE generation is related to soil density. In a field monitoring situation, the placement of backfill within the borehole is critical to the response of the waveguide system at small strains as demonstrated by Dixon et al. (2003). High backfill density can be achieved in a borehole by placing and compacting in lifts. 
A relationship between displacement and $\mathrm{AE}$ rates can be obtained using the data presented in Figure 3 by calculating the gradient of a best fit straight line through each set of results and plotting this gradient against the actual applied displacement rate (Figure 4). A line can then be drawn through the plotted points in Figure 4 to produce a relationship between event rate gradient and rate of displacement. This graph can be used to convert recorded $\mathrm{AE}$ event rates from a slope monitoring programme using the active waveguide into rates of displacement. A linear relationship was not obtained as the data for the $1 \mathrm{~mm}$ displacement rate falls below a straight line extrapolated through the three slower rates. At high rates of $\mathrm{AE}$ generation it is possible for events to overlap, resulting in an underestimate of event rates. However this does not affect the clear differentiation between the $1 \mathrm{~mm}$ and $0.1 \mathrm{~mm}$ results. It should be noted that the relationship presented in this paper is specific to the backfill type, waveguide and monitoring system used in this study. However, a similar relationship could be derived for any alternative waveguide system by reproducing the experimental procedure outlined above and producing an equivalent Figure 4.

\section{Active waveguide shear tests}

Large scale shear tests were conducted to investigate whether the data obtained from the compression testing, and hence the derived relationship between $\mathrm{AE}$ and displacement, would be valid for shearing mechanisms more realistic to those experienced in deforming slopes. Figure 5a) shows a schematic diagram of the loading and measuring equipment, Figure 5b) shows the mechanism of deformation and Figure 5c) the internal arrangement of the active waveguide within the clay filled box following deformation. Displacement controlled shear tests were performed upon an active waveguide assembly encased within a body of low plasticity silty clay, 
representing host soil. A horizontal column of clay $(1.48 \mathrm{~m}$ long $\mathrm{x} 0.64 \mathrm{~m}$ wide $\mathrm{x}$ $0.49 \mathrm{~m}$ high) containing the active waveguide was formed by compaction within wooden formwork that was divided into three sections. The middle section could be displaced laterally relative to the two end sections to generate deformation of the clay surround (Figure 5b), and hence of the active waveguide assembly. This was housed within a reinforced steel box of dimensions $1.4 \times 1.7 \times 1.4$ metres, which provided a rigid support for the wooden formwork and a reaction for the mechanical screw jack. The middle section was displaced at a constant rate horizontally using the jack. The aim was to generate a similar mechanism to a developing shear surface in a slope, although it should be noted that two shear zones were created by the draw-like mechanism used. The same types of steel tube waveguide and gravel backfill were used as in the compression tests. The backfill had a square cross-section of dimensions 160mm x 160mm.

Three tests were performed, with each test constructed using new gravel and remoulded clay. Two tests were performed at the equivalent of a moderate displacement rate of approximately $0.2 \mathrm{~mm} / \mathrm{min}$, and one was performed at the equivalent of a slow displacement rate of approximately $0.02 \mathrm{~mm} / \mathrm{min}$. AE instrumentation and settings were identical to those used in the compression tests. The clay had a liquid limit of $30 \%$ and a plastic limit of $19 \%$ and was placed at a moisture content of $15 \%$, giving an average undrained shear strength of $83 \mathrm{kPa}$. At this moisture content the clay was still easily moulded for placing within the box. A load cell was placed between the screw jack and the middle section, and displacement transducers were located to measure displacement of the middle section relative to sections either side (Figure 5a). The AE sensor was located on the waveguide $1.8 \mathrm{~m}$ from the centre 
of the middle section. This position was chosen to maintain similar testing conditions as used in the compression experiments.

$\mathrm{AE}$ data from the three tests is presented in Figure 6 as log event rate against log time. The data has been superimposed onto the results obtained from the compression tests. The two tests conducted at a displacement rate of $0.2 \mathrm{~mm} / \mathrm{min}$ are in agreement with each other. Also, the large scale shear AE data differentiates the order of magnitude of deformation employed and is comparable to the compression data. However, the comparison demonstrates a reduction in the levels of $\mathrm{AE}$ measured in the large scale tests. For example, after $10 \mathrm{~mm}$ of displacement at a moderate strain rate in the large shear test a final event rate close to 267 events per minute was achieved compared with the compression test at a similar rate of displacement that reached 800 events per minute at the end of the experiment. This could be a result of the different modes of backfill deformation in the compression and shear experiments. However, it could also be explained by the location of displacement measurements in the large shear tests. In the compression tests the deformation of the gravel was measured directly (i.e. change in diameter of waveguide assembly), while in the large shear tests, displacement of the wooden formwork in the middle section was measured and therefore it is not known how much displacement was directly experienced by the waveguide. Compression and deformation of the clay surround was observed during dismantling of each experiment, with a gap forming at the leading edge of the assembly between the clay and formwork. This indicates that deformation of the clay surround, and hence gravel, was lower than that measured on the outside of the confining container, resulting in an over estimate of the gravel displacement rate, and hence generation of reduced $\mathrm{AE}$. The generated $\mathrm{AE}$ is representative of the deforming 
gravel within the active waveguide and only indirectly related to the shear state of the surrounding clay. It should be noted that the clay deformed plastically and distinct shear zones did not form (Figure 5c). This will have resulted in distributed shearing of the gravel and hence possibly in lower levels of generated AE.

\section{Validation of approach and sensitivity to rate changes}

To validate the proposed method of using AE event rates to obtain displacement rates, and to assess the sensitivity of generated AE to changes in displacement rate, a 'blind' experiment was carried out. Displacement rates were altered several times during a compression test and these rates were not known by the person analysing the AE data. The compression test procedure as described above was employed with displacement rates acting for different lengths of time. The aim was to investigate sensitivity of the $\mathrm{AE}$ interpretation procedure to identify the magnitude of, and changes in, the rate of backfill displacement. The experiment was controlled by an independent person who had the discretion to select different rates of displacement from a set choice, which was dictated by the gearing of the compression cell, and also the times over which these would act on the active waveguide. The rates of displacement used are shown in Table 2. They were different to those in the original compression tests, but still represented a range of orders of magnitude of displacement rates.

Interpretation of displacement rates was based solely on the measured time related event count information. The measured cumulative event count relationship with time is shown in Figure 7. A total of 9 separate rates were identified (denoted stages 1 to 9 ) by visually examining the graph for distinct changes in the gradient of the event count versus time relationship. Lines shown across the graph indicate the actual timing of changes in displacement rate. The predicted and actual start and finish times for each 
stage are listed in Table 3. It can be seen that errors in predicting times of displacement rate change from observing the AE behaviour were small. The largest error of 1.8 minutes was obtained for the slowest displacement rate of $0.0018 \mathrm{~mm} / \mathrm{min}$, which is equivalent to $0.003 \mathrm{~mm}$ of deformation. Smaller time errors were obtained for faster rates. This small delay in registering a change in displacement rate is considered acceptable in relation to slope monitoring practice.

Using the AE/displacement rate relationship shown in Figure 4, the AE event rates from the blind test were used to obtain rates of displacement and these are compared to the actual applied rates in Table 3. Nine separate displacement rates were calculated (i.e. one for each stage of the test as identified by the changes in slope as outlined above). Stages 4 and 8 each produced a negative gradient of event rate (i.e. over time the event rate decreased). It was concluded that this must signify that displacement had stopped, which was in fact the case. Dixon et al. (2003), among others, demonstrated that the generation of $\mathrm{AE}$ only occurs within soil when the maximum previous stress has been exceeded (i.e. the Kaiser effect). If the stress upon a soil sample remains constant or is reduced, the AE rate will reduce until generation stops. With the exception of stages 5 and 9, the displacement rates were classified into their correct order of magnitude. Displacement rates in stages 5 and 9 were over estimated by one order of magnitude, and both stages followed a period of zero displacement. It is not known why this occurred. It is possible that if the time these rates acted over had been extended, the AE rates would have reduced to the correct range (i.e. the over estimate might only occur for a short period of time following a period of zero displacement). Although this is a conservative error, further research is 
required into this behaviour. Full details of all the experiments and results are presented in Spriggs (2005).

The main outcome from this blind test is proof that measured AE event counts from a deforming active waveguide can be used to quantify rates of displacement, and the time over which these act, without prior knowledge. In addition, changes in rate of displacement (i.e. increasing, decreasing and no displacements) were identified within a few minutes of the change occurring even at very slow rates. This is an important result as identifying and quantifying an increasing rate of displacement provide a key indicator of decreasing slope instability and hence potential for large scale movements. Conversely, measurement of decreasing displacement rates indicate increasing stability (e.g. the success of stabilisation measures).

\section{Additional considerations and ongoing research}

The waveguide lengths used in this study are relatively short (i.e. $<3$ metres), and hence attenuation of $\mathrm{AE}$ during propagation of the signal along the steel tube was minimal. The use of longer waveguides during slope monitoring requires quantification of the amount of attenuation so that a correction can be applied to the AE event rates (i.e. event rates will be reduced by long propagation distances and by connections between lengths of tubing). This means that the location of the $\mathrm{AE}$ generating source (i.e. deforming shear surface) is required. A method has been developed to obtain this information based on analysis of AE wave mode arrival times (Spriggs 2005). In addition, attenuation rates for the steel tube and connections have been measured. Obtaining the depth to the developing shear surface also aids 
assessment of the mode of slope failure and identification of spurious AE data (i.e. background $\mathrm{AE}$ generated near the ground surface).

The AE technique detailed in this paper has the potential to be used as a real-time monitoring system for assessing stability of slopes that undergo pre-failure deformations. It has been demonstrated that it is sensitive to small slope deformations (Dixon et al. 2003), can detect changes in displacement rate within a few minutes of it occurring even at very slow rates and can be used to differentiate between orders of magnitude of displacement rate. It has the potential to complement existing real-time monitoring systems such as in-place inclinometers and TRD probes, and in some applications it may prove to have superior performance. However, a rigorous comparison can not yet be made due to limited information on field performance of the AE system and the need for a direct comparison with existing techniques. A field trial of a real-time AE monitoring system is currently in progress, including the use of in-place inclinometers, and this will enable a comparison of performance to be made. Cost of the AE monitoring system is currently relatively high compared to traditional techniques as it is still a prototype system, however there is significant scope to reduce this cost once a specification for the AE instrumentation has been finalised.

\section{Summary}

Previous research has demonstrated that acoustic emission monitoring of slopes using active waveguides can indicate instability, with AE rates linked to displacement rates. This paper details a series of laboratory experiments to investigate the relationship between $\mathrm{AE}$ and displacement of an active waveguide. It has been found that event rates are directly related to displacement rates over a range that is consistent with 
standard landslide movement classification (i.e. 1 to $0.001 \mathrm{~mm}$ per minute). Using AE rates it is possible to differentiate deformation rates by an order of magnitude using a relationship between the gradient of the event count rate with time and the deformation rate (Figure 4).

Validation of the approach using a blind test demonstrated that both increases and decreases in deformation rate, within an order of magnitude, can be identified. A decrease in event rate indicates increasing stability and means the technique can be used to monitor and assess time dependent changes in stability in response to remediation works. The sensitivity of $\mathrm{AE}$ monitoring to very slow rates of displacement, coupled with the ability to identify a change in displacement rate within two minutes of the change occurring, even at very slow rates, is important in situations where slope movements are suddenly triggered or displacements accelerate in response to a destabilising event (e.g. in response to intense rainfall). This means that $\mathrm{AE}$ monitoring has the required sensitivity for use as an early warning system for slope instability. Field trial of a real-time AE monitoring system is currently in progress, including a comparison with traditional instrumentation. This will enable an assessment of applications where AE monitoring can provide benefits over existing techniques.

A qualitative guide was proposed by Koerner et al. (1981) for using AE in slope monitoring. Based on the active waveguide used in this study, a framework is proposed based on quantification of AE to derive displacement rates and hence assess status of the slope, as shown in Table 4. 


\section{Acknowledgements}

The Authors wish to thank Dr Roger Hill for his advice and support in the early stages of the project. 


\section{References}

ASTM 2002. Standard guide for mounting piezoelectric acoustic emission sensors. American National Standard, Designation: E 650-97: 277-279.

Dixon, N., Hill, R., and Kavanagh, J. 2003. Acoustic emission monitoring of slope instability: Development of an active wave guide system. Institution of Civil Engineers Geotechnical Engineering Journal, 156, 2, 83-95.

Koerner, R. M., McCabe, W. M., and Lord, A. E. 1981. Acoustic emission behaviour and monitoring of soils. In Acoustic Emission in Geotechnical Practice, American Society for Testing and Materials, ASTM STP 750, pp. 93-141.

Kousteni, A. 2002. Investigation of Acoustic Emission Waveguide Systems for Detecting Slope Instability. PhD Thesis, Department of Civil and Structural Engineering, The Nottingham Trent University, UK.

Nakajima, I., Negishi, M., Ujihira, M., and Tanabe, T. 1991. Application of the acoustic emission monitoring rod to landslide measurement. Proceedings of the $5^{\text {th }}$ Conference on Acoustic Emission/Microseismic Activity in Geologic Structures and Materials, Pennsylvania State University, pp. 505-520.

Shiotani, T., and Ohtsu, M. 1999. Prediction of slope failure based on AE activity. In Acoustic Emission: Standards and Technology update (Vahaviolos, S.J. (Ed.)), American Society for Testing Materials, ASTM STP, Pennsylvania, 1353, pp. 157-172.

Spriggs, M. 2005. Quantification of acoustic emission from soils for predicting landslide failure. PhD Thesis, Department of Civil and Building Engineering, Loughborough University, UK.

Transport Research Board 1978. Landslides, Analysis and Control. National Academy of Sciences. 


\section{Tables}

Table 1 Classification of landslide movement rates (after Transport Research Board 1978) and related displacement rates used in active waveguide compression tests

\begin{tabular}{|c|c|c|}
\hline \multicolumn{2}{|c|}{$\begin{array}{c}\text { Transport Research Board (1978) } \\
\text { Landslide Classification }\end{array}$} & \multirow{2}{*}{$\begin{array}{c}\text { Displacement rates } \\
\text { used in waveguide } \\
\text { compression tests } \\
(\mathrm{mm} / \mathrm{min})\end{array}$} \\
\hline Description & $\begin{array}{l}\text { Displacement rate } \\
\text { (mm/min) }\end{array}$ & \\
\hline $\begin{array}{l}\text { Extremely } \\
\text { Rapid }\end{array}$ & $>180000$ & - \\
\hline Very Rapid & 180000 to 300 & - \\
\hline Rapid & 300 to 1.04 & 1.1 \\
\hline Moderate & 1.04 to 0.034 & 0.10 \\
\hline Slow & 0.034 to 0.0034 & 0.012 \\
\hline Very Slow & 0.0034 to 0.00011 & 0.0012 \\
\hline
\end{tabular}


Table 2 Active waveguide compression rates used in 'blind' test

\begin{tabular}{lc}
\hline $\begin{array}{c}\text { Landslide rate } \\
\text { description }\end{array}$ & $\begin{array}{c}\text { Displacement rates used in } \\
\text { 'blind' compression tests } \\
\text { (mm/min) }\end{array}$ \\
\hline Rapid & 1.1 \\
Moderate & 0.22 \\
Slow & 0.044 \\
Very slow & 0.0018 \\
\hline
\end{tabular}


Table 3 Predicted and measured displacement rates and time intervals for 'blind' test

\begin{tabular}{cccccccc}
\hline $\begin{array}{c}\text { Stage } \\
\text { No. }\end{array}$ & \multicolumn{3}{c}{ Calculated values } \\
\cline { 2 - 8 } & $\begin{array}{c}\text { From } \\
\text { (hours) }\end{array}$ & $\begin{array}{c}\text { To } \\
\text { (hours) }\end{array}$ & $\begin{array}{c}\text { Gradient of } \\
\text { trend line }(\text { event } \\
\text { counts/hr) }\end{array}$ & $\begin{array}{c}\text { Rate of } \\
\text { displacement } \\
(\mathrm{mm} / \mathrm{min})\end{array}$ & $\begin{array}{c}\text { Rate of } \\
\text { displacement } \\
(\mathrm{mm} / \mathrm{min})\end{array}$ & $\begin{array}{c}\text { From } \\
\text { (hours) }\end{array}$ & $\begin{array}{c}\text { To } \\
\text { (hours) }\end{array}$ \\
\hline 1 & 0.00 & 0.05 & 556 & 3.3 & 1.1 & 0.00 & 0.04 \\
2 & 0.05 & 0.44 & 2.7 & 0.054 & 0.044 & 0.04 & 0.43 \\
3 & 0.44 & 3.46 & 0.35 & 0.0067 & 0.0018 & 0.43 & 3.43 \\
4 & 3.46 & 4.47 & -0.00028 & - & 0 & 3.43 & 4.44 \\
5 & 4.47 & 4.61 & 13 & 0.13 & 0.044 & 4.44 & 4.61 \\
6 & 4.61 & 4.78 & 51 & 0.33 & 0.22 & 4.61 & 4.78 \\
7 & 4.78 & 4.80 & 255 & 1.1 & 1.1 & 4.78 & 4.79 \\
8 & 4.80 & 5.13 & -0.012 & - & 0 & 4.79 & 5.13 \\
9 & 5.13 & 5.92 & 0.11 & 0.013 & 0.0018 & 5.13 & 5.92 \\
\hline
\end{tabular}


Table 4 Assessment of slope displacement rates and state using quantified AE generated by the active waveguide used in this study

\begin{tabular}{|l|c|c|l|}
\hline Description & $\begin{array}{c}\text { Slope } \\
\text { deformation } \\
\text { rate (mm/min) }\end{array}$ & $\begin{array}{c}\text { Gradient of } \\
\text { AE event rate } \\
\text { (Events/min } \mathbf{~} \text { ) }\end{array}$ & \multicolumn{1}{|c|}{ State of slope } \\
\hline Rapid & $>1$ & $>100$ & $\begin{array}{l}\text { Slope is undergoing large } \\
\text { deformations and is likely to be } \\
\text { in a state of failure. Urgent } \\
\text { need to implement public safety } \\
\text { measures }\end{array}$ \\
\hline Moderate & 0.1 & 100 to 1 & $\begin{array}{l}\text { Substantial deformations and } \\
\text { considered unstable, immediate } \\
\text { remedial and public safety } \\
\text { measures required }\end{array}$ \\
\hline Slow & 0.01 & 1 to 0.01 & $\begin{array}{l}\text { Deforming slightly but } \\
\text { marginally stable, continued } \\
\text { monitoring is necessary }\end{array}$ \\
\hline Very Slow & $<0.001$ & $<0.01$ & $\begin{array}{l}\text { Slope can be considered } \\
\text { essentially stable }\end{array}$ \\
\hline
\end{tabular}


Figures

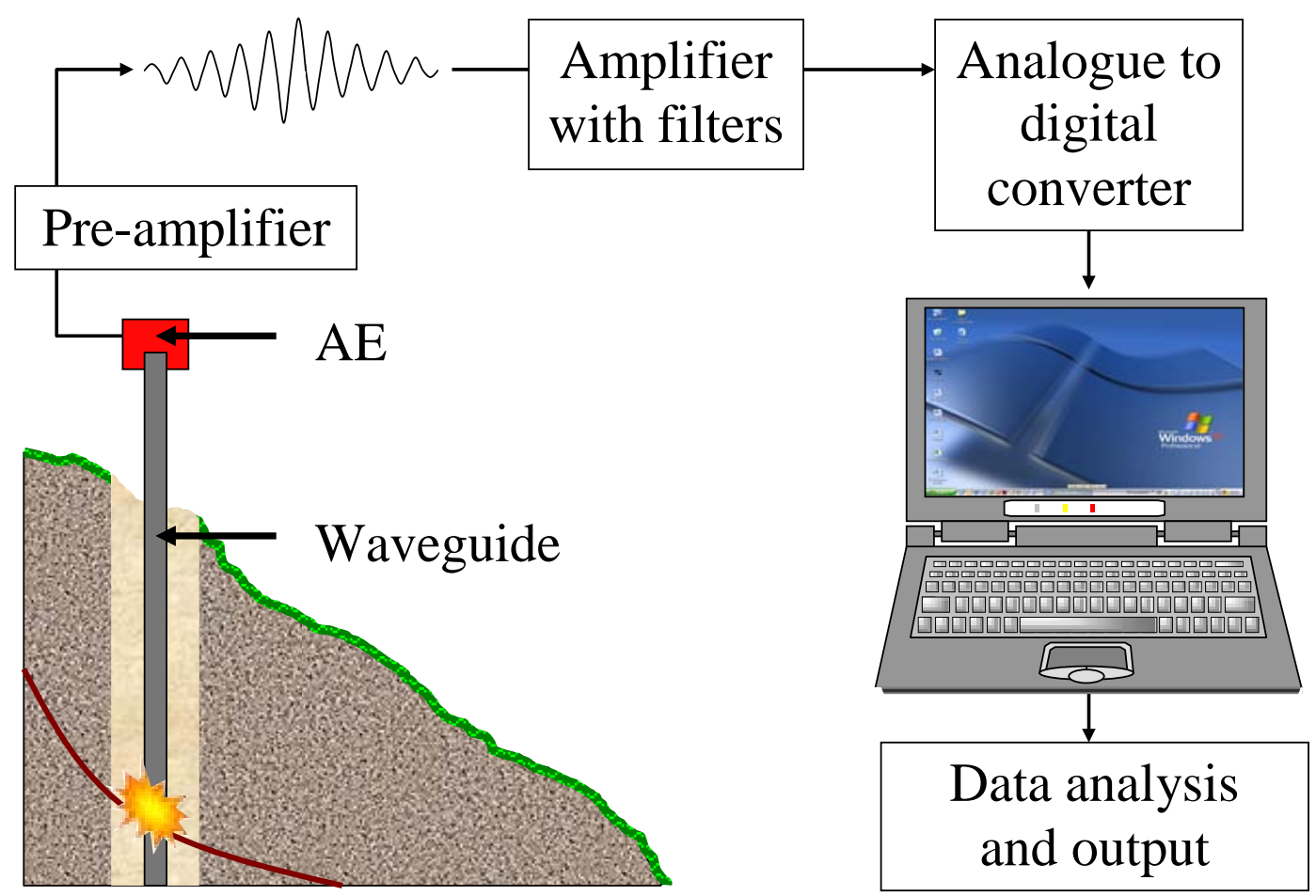

Figure 1 Schematic of slope AE monitoring system 

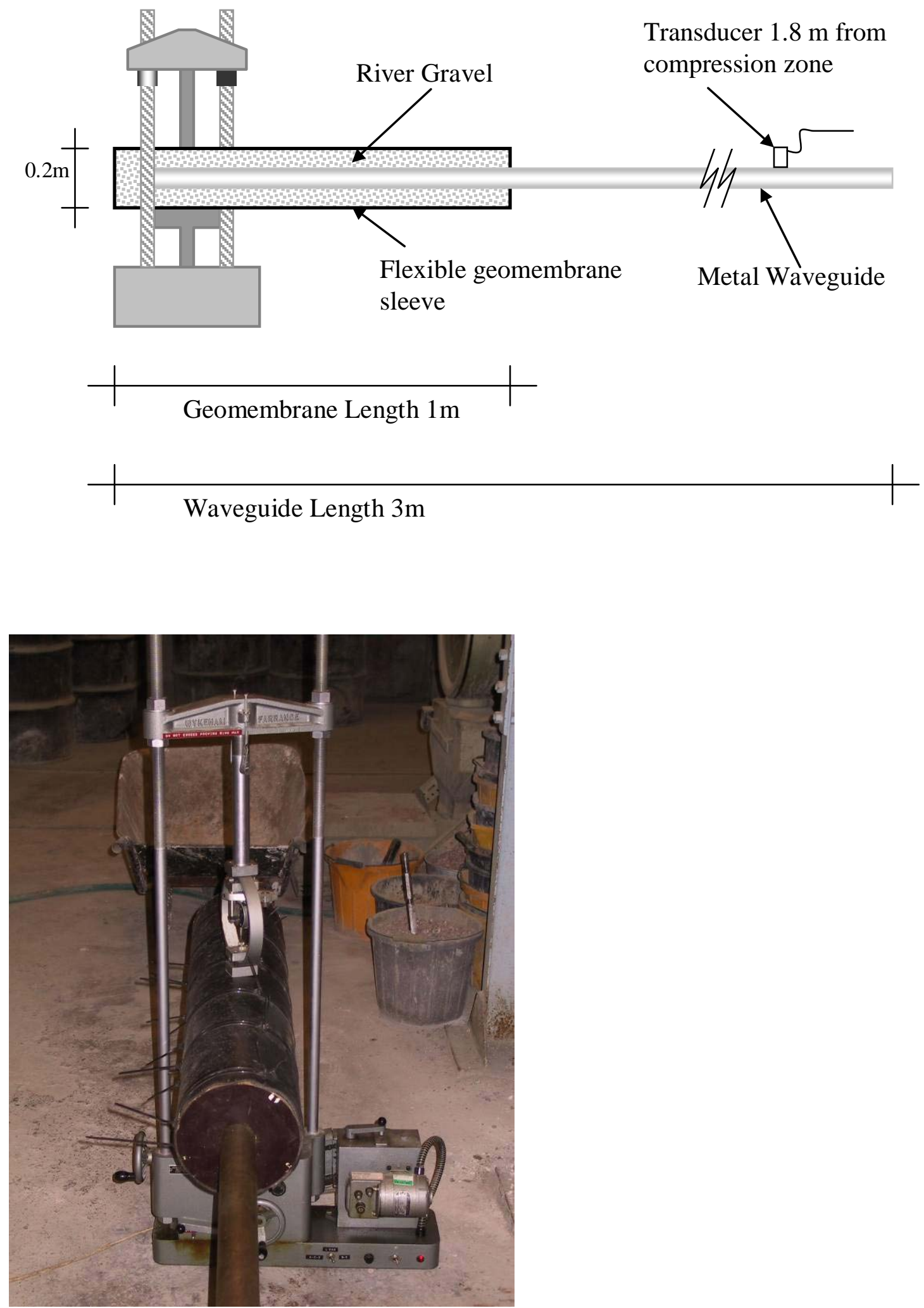

Figure 2 a) Schematic of active waveguide compression experiment and b) picture of apparatus 


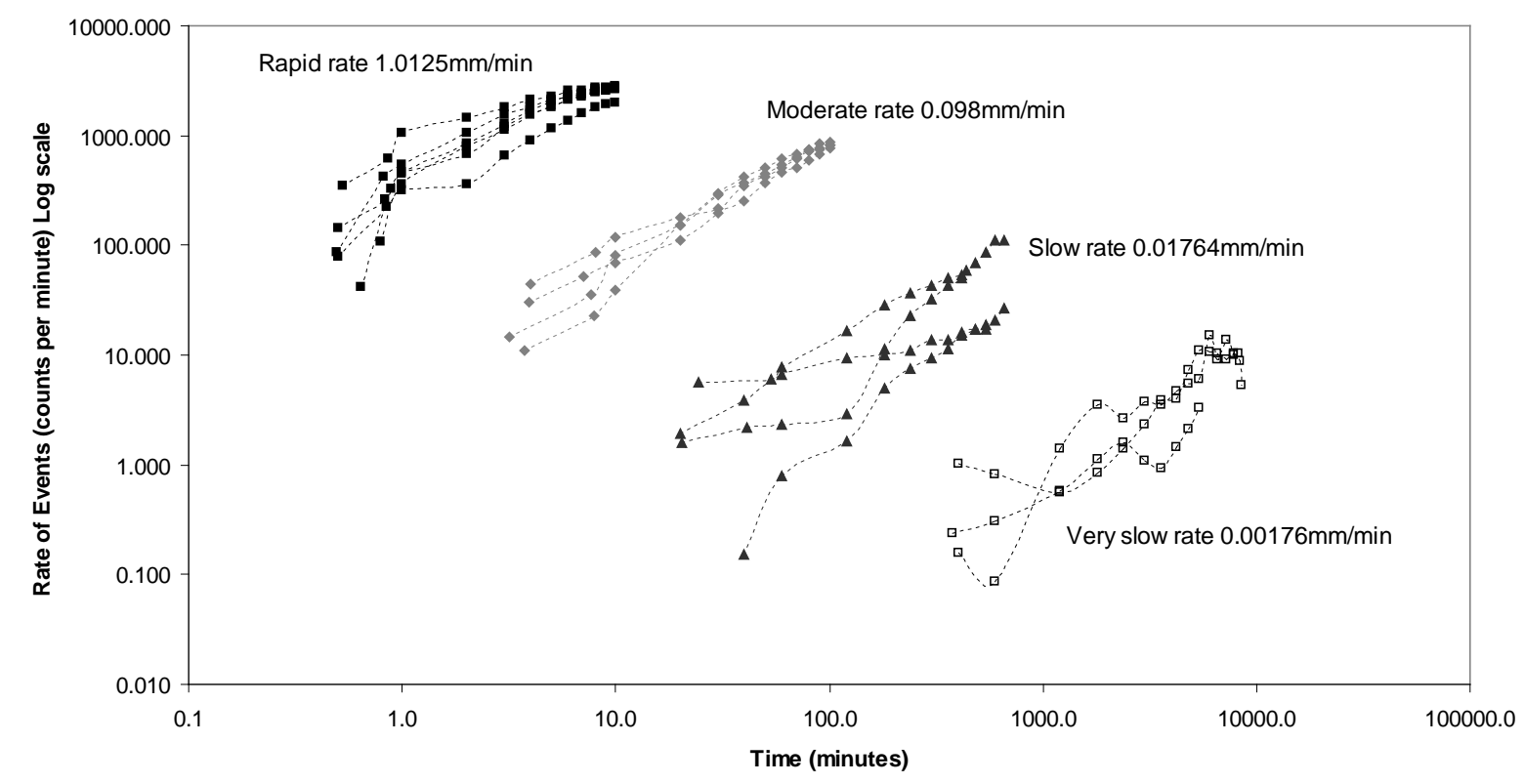

Figure 3 Relationship between log $\mathrm{AE}$ event rate and log time for active waveguide compression tests using a range of displacement rates from 0.001 to $1 \mathrm{~mm}$ per minute 


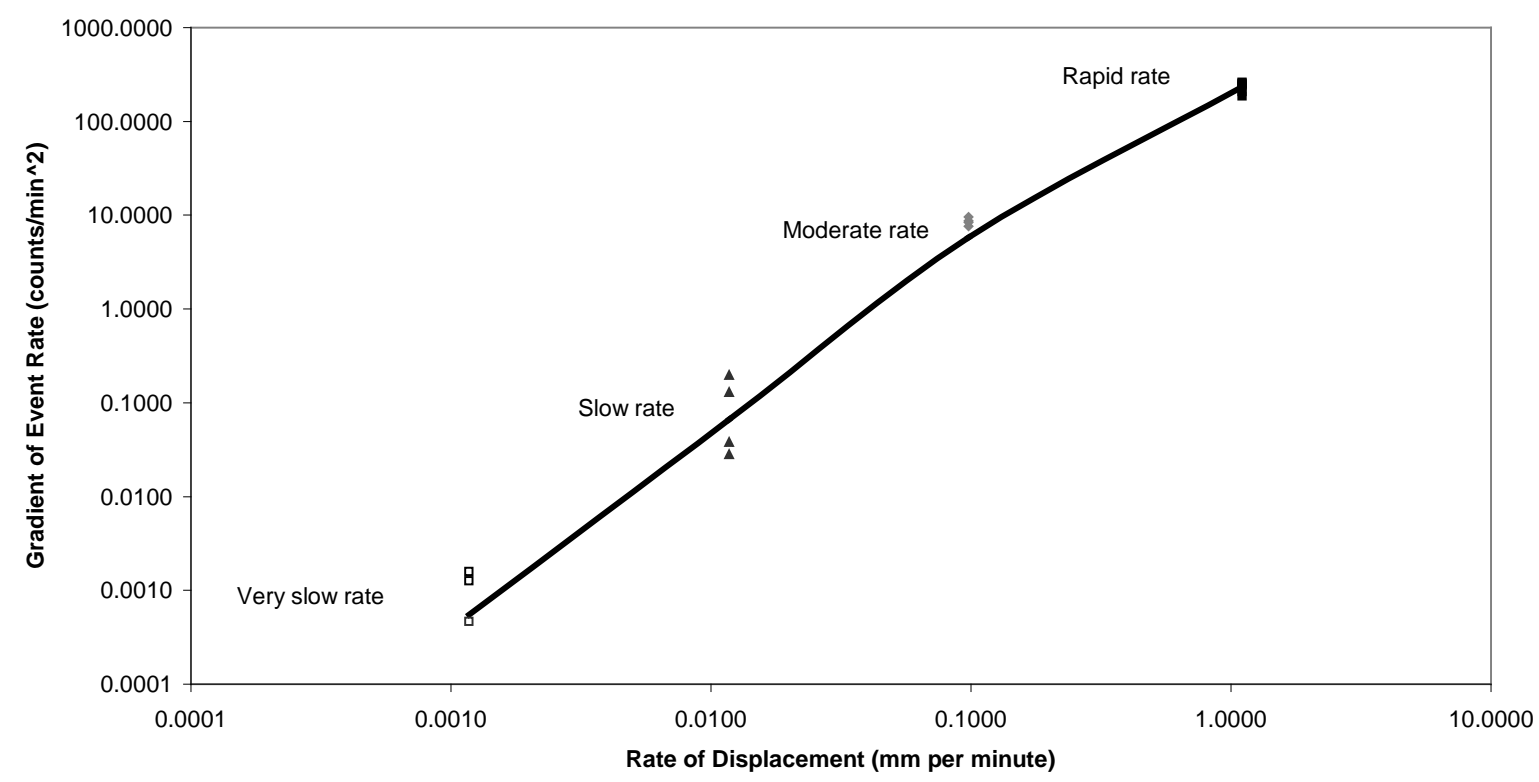

Figure 4 Relationship between measured AE event rate gradient and applied displacement rate, with the best fit trend line shown 


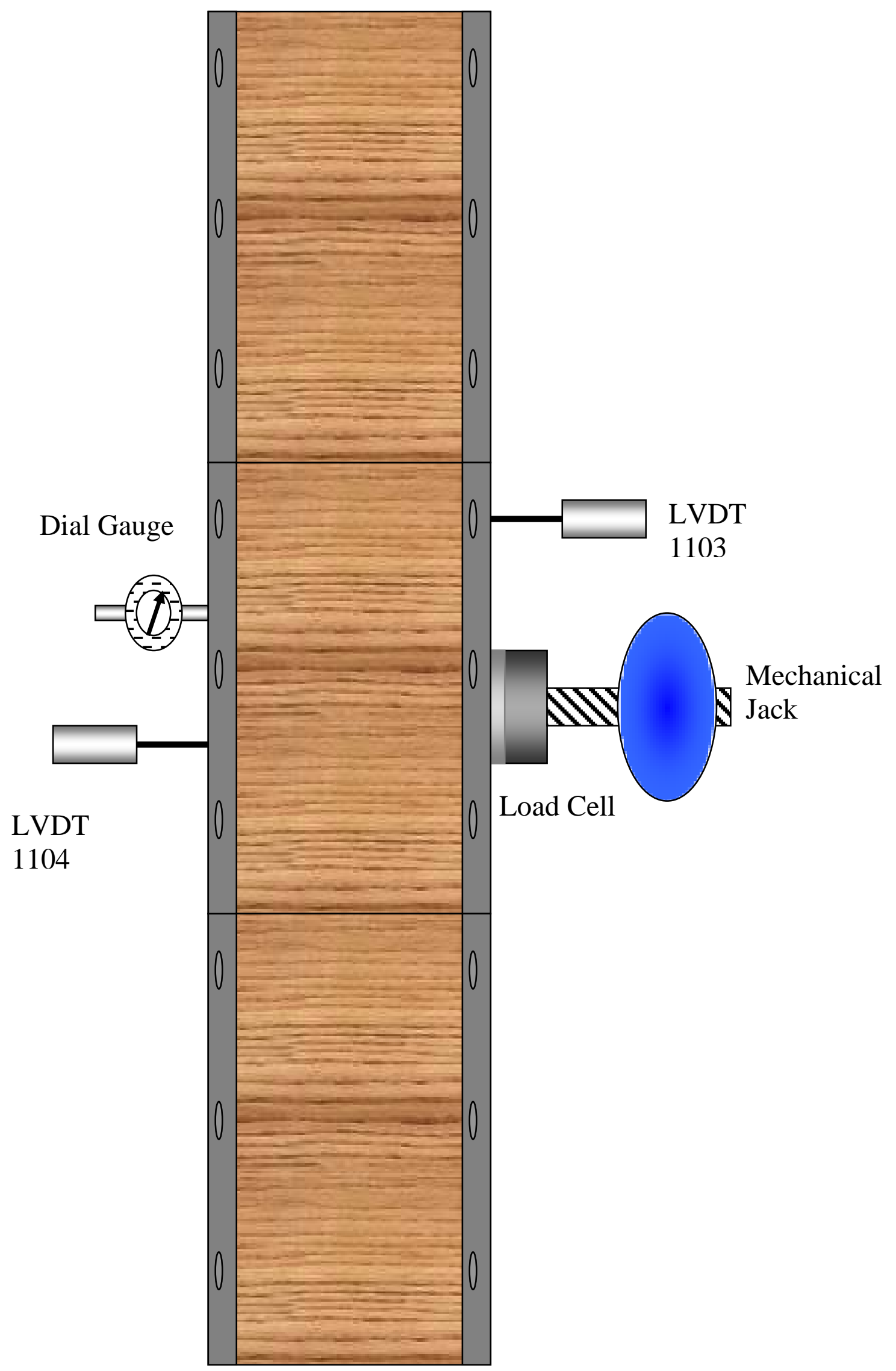

Figure 5 a) 


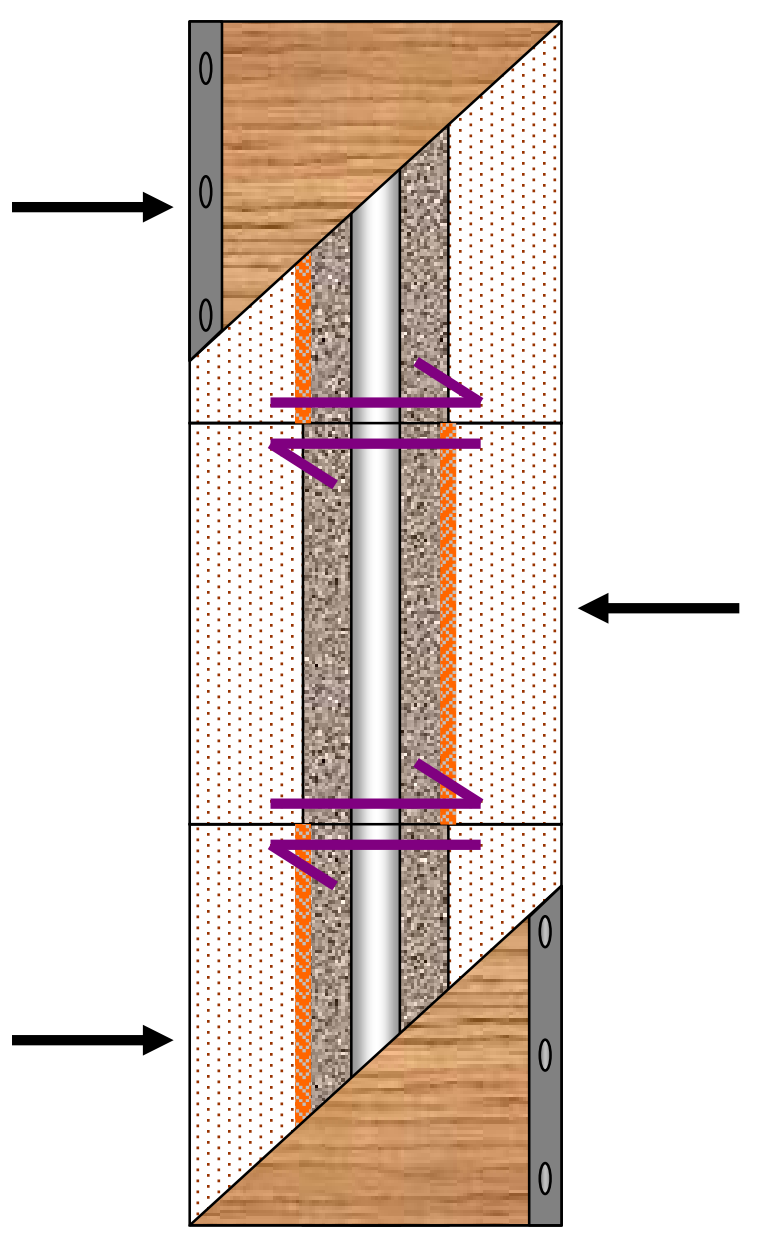

Key:

Waveguide

River gravel

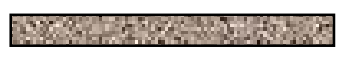

Clay

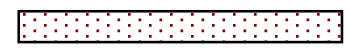

Direction of load

Compression zone

Shear plane

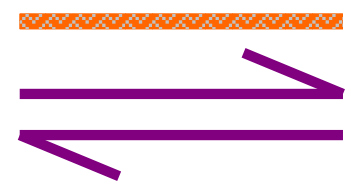

Figure 5 b) 


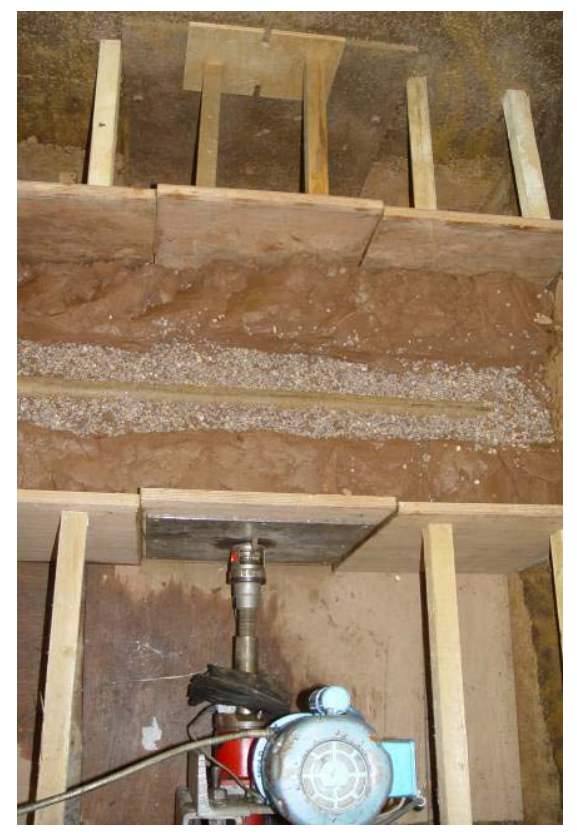

Figure 5 c)

Figure 5a) shows a schematic diagram of the loading and measuring equipment used in the large shear tests, 5b) shows the mechanism of deformation and Figure 5c) the internal arrangement of the active waveguide within the clay filled box following deformation and removal of top cover 


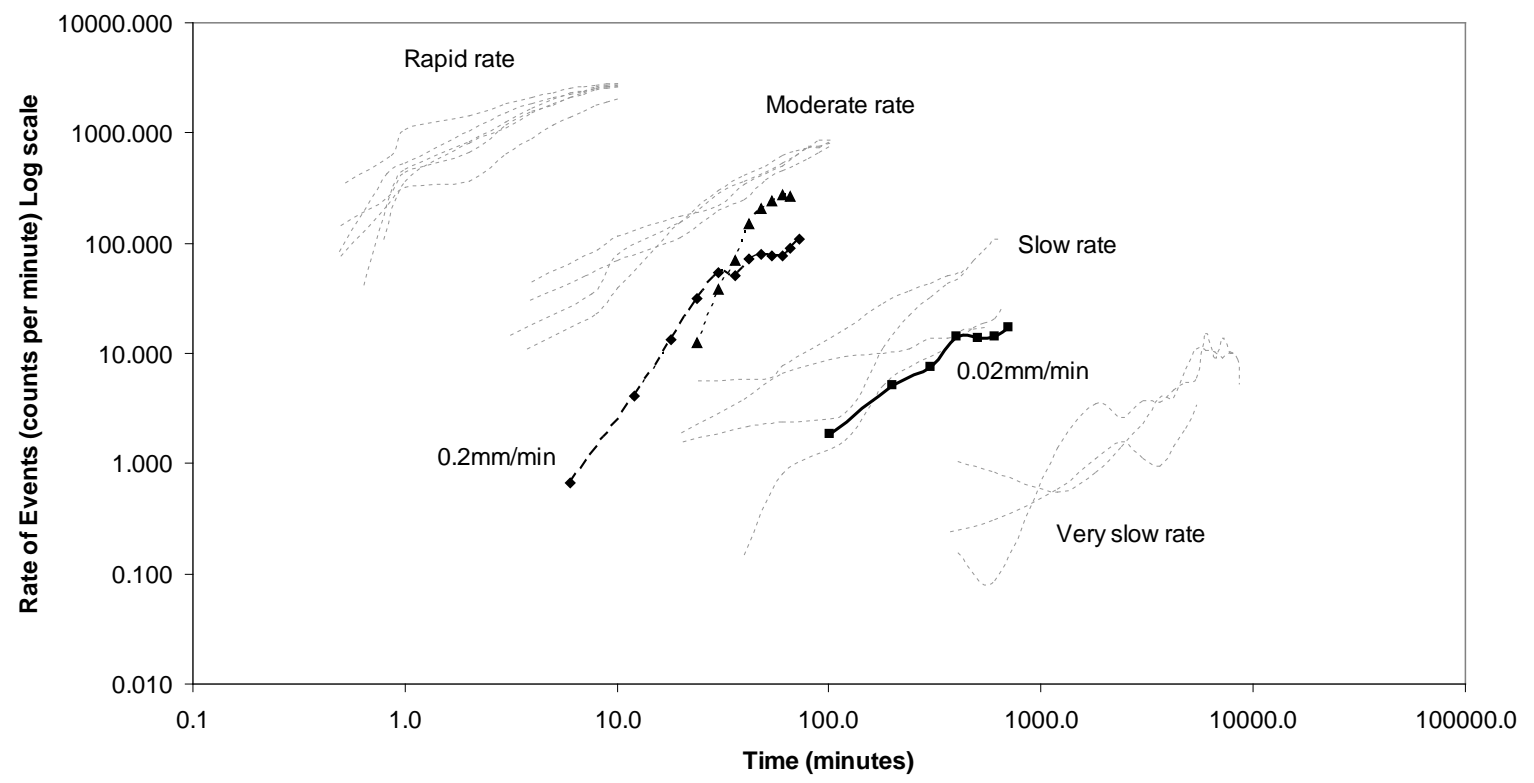

Figure 6 Log AE event rate vs. log time relationship for active waveguide large scale shear tests (bold), super imposed on compression test results for comparison (faint) 


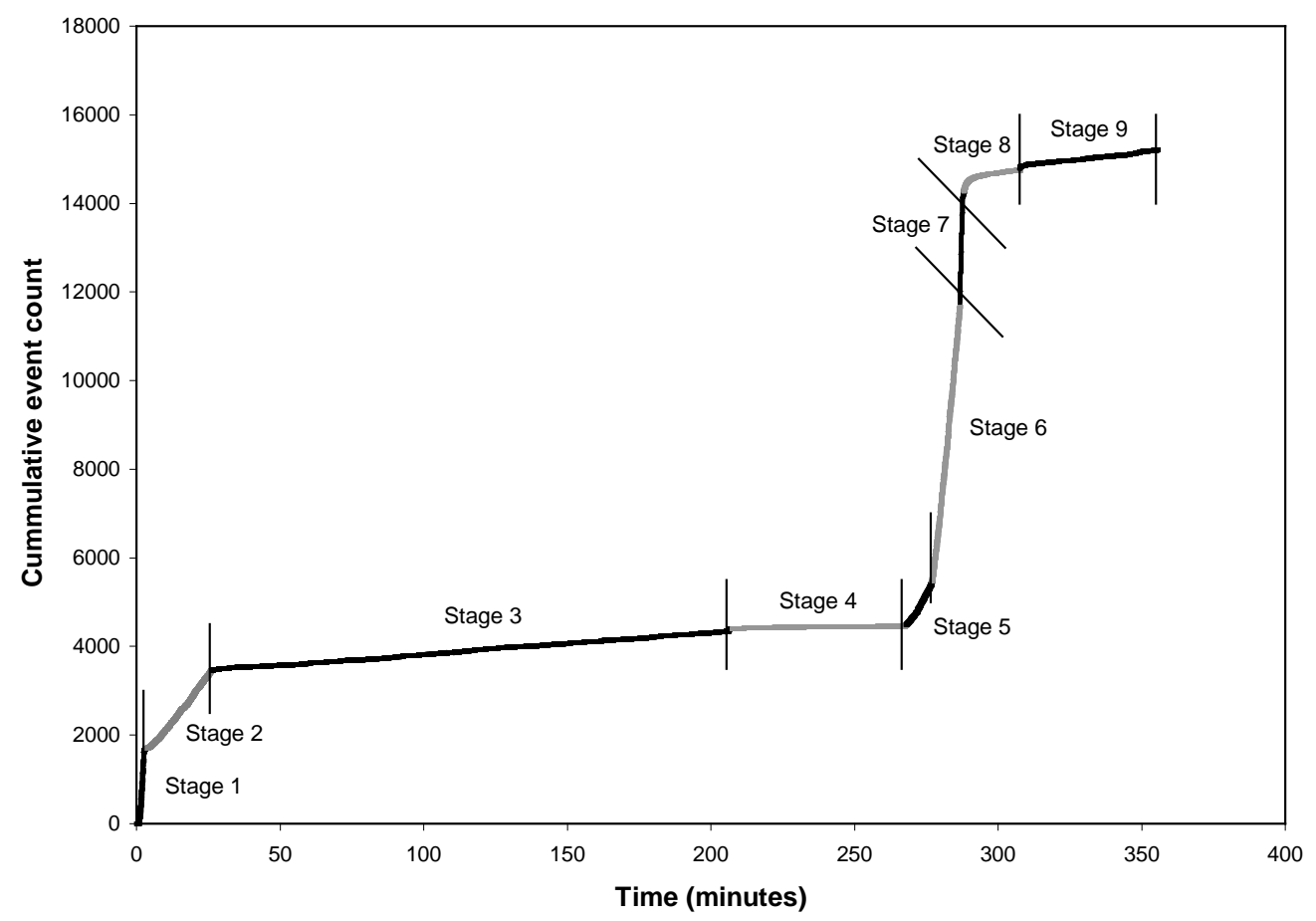

Figure $7 \quad$ AE event rate vs. time behaviour for validation 'blind' test, showing interpreted 9 stages of displacement (i.e. different rates) and actual times of displacement rate changes (indicated by position of lines across graph) 